\title{
O valor da fenomenologia na superação do neokantismo
}

\author{
Margarida Amoedo \\ In memoriam
}

\begin{abstract}
João Paisana foi, em Portugal, uma das pessoas capazes de, com clareza e originalidade, trabalhar em fenomenologia. Interrompidas abruptamente as suas indagações, aqui deixamos alguns resultados das nossas, realizadas em torno de um autor que também teve, nas suas circunstâncias, papel importante em relação ao movimento fenomenológico.
\end{abstract}

Num texto escrito em 1934, José Ortega y Gasset afirmou a fenomenologia como um "prodigioso instrumento". Vamos contextualizar e interpretar esta referência, porquanto ela reflecte uma apreciação dos primeiros passos da filosofia fenomenológica mais significativa do que a brevidade da expressão faz crer. Com efeito, embora seja natural - em vista da data de redacção do escrito em que surgem - que sintetizem já uma avaliação alargada do pensador espanhol quanto às potencialidades do método fenomenológico, aqueles termos visavam principalmente traduzir, o balanço da reacção, vivida no início da segunda década do Século XX pelos jovens discípulos da Escola de Marburg, ao neokantismo dos seus mestres. Ortega y Gasset, que se contava entre esses discípulos juntamente com, por exemplo, Nicolai Hartmann, Paul Scheffer, ou Heinz Heimsoeth, leva-nos com a sua anamnese a atender, em particular, ao significado da fenomenologia na superação de limites do construtivismo neokantiano.

Ao seguirmos a pista da afirmação de Ortega y Gasset, iremos remeter-nos, inevitavelmente, a uma leitura situada da importância do método proposto por Edmund Husserl; contudo, para além das ilações biográficas que disso haverá que retirar, poder-se-á realçar o carácter exemplar da fecundidade fenomenológica a partir do caso concreto aqui tomado.

\section{Influências da experiência alemā}

O conhecimento das relações do filósofo madrileno com o neokantismo marburguiano são indispensáveis para o entendimento profundo da edificação de

1 ORTEGA Y GASSET, José, $P$. A., in O. C., VIII, p. 42. Tal como nesta nota, usaremos doravante, ein rodapé, a abreviatura $P$. A., para citar o texto - escrito em 1934 - intitulado Prólogo para alemanes, e a abreviatura O. C., em vez de Obras Completas, na edição de 1983, da Alianza Editorial, com 12 tomos que identificaremos, consoante o caso, em numeração romana. 
um pensamento próprio, cuja consolidação muito deveu à experiência alemã, ocorrida em dois períodos compreendidos entre 1905 e 1911, nas Universidades de Leipzig, Berlin e Marburg. E precisamos de ter presente todo o entusiasmo posto pelo jovem Ortega na intervenção pública, bem como as motivações intelectuais e pedagógicas com esta desde sempre entretecidas, para compreender a força do papel formativo decisivo que para ele teve o encontro com a filosofia alemã e, em especial, com o magistério de Hermann Cohen e de Paul Natorp.

De facto, sem que se possa subestimar os estudos que realizou em Leipzig (de Alemão, Latim, Grego, História Moderna Alemã, Histologia, Osteologia, e ainda de temas e obras do classicismo espanhol) e em Berlin (de Psicologia, Ética e Estética), foi sobretudo em Marburg que Ortega contactou com a escola filosófica que marcaria uma etapa inicial de inspiração alemã na sua meditação, conforme assinalam vários autores fundamentais de obras a seu respeito, ainda que não coincidam na periodização da mesma, nem na sua designação. Por exemplo, Ferrater Mora, que considera haver, apesar de um só pensamento fundamental, três grandes estádios na evolução da filosofia orteguiana, identifica como primeiro o do objectivismo (de 1902 a 1914) ${ }^{2}$ e Morón Arroyo, em El sistema de Ortega y Gasset, aponta, a preceder três outros estádios, um de 1907 a 1914, de reflexo neokantiano ${ }^{3}$. Por seu turno, Cerezo Galán procura antes, no interessante livro La voluntad de aventura, partir do binómio cultura/vida que atravessa toda a obra de Ortega e ver como ele vai conferindo uma articulação interna às etapas do pensamento do autor estudado. Adoptando um critério de abordagem singular, que permite acompanhar o desenvolvimento das concepções de Ortega a partir de dentro, Cerezo Galán não deixa de sustentar o carácter neokantiano da primeira etapa desse pensamento ${ }^{4}$.

É possível, na verdade, ilustrar como desde cedo se revela, em escritos de índole vária, a presença de elementos doutrinais relacionáveis com os filósofos de Marburg. Assim, no artigo Sobre los estudios clásicos, de 1907, lemos: “(...) tengo a lo clásico, no sólo por el embrión de la cultura, sino por el sentido perenne de ella" e "cultura vale en propiedad como cultura del hombre, y significa elaboración y henchimiento progresivo de lo específicamente humano"s. Estas palavras, com o seu propósito de definir o humano em função da cultura, conjugam-se sem dúvida com as teses neokantianas, em que todo o conhecimento - mesmo a Ética e a Estética -, desde que sistematizado segundo o modelo físico-matemático, se concebe como lei, norma ou objectividade; por consequência, o conhecimento válido é, não só o acessível às ciências matemático-naturais, mas também o conhecimento do humano enquanto objectivado. Cultura é nesta concepção o oposto dos impulsos, espontaneidade e inclinações do indivíduo, o oposto da subjectividade, que era particularmente temida por Cohen.

É envolvido por algumas dessas posições fundamentais neokantianas que, em certos textos, Ortega se declara abertamente contra o subjectivismo, numerosas vezes por si considerado um defeito dos seus compatriotas. "Por higiene espiritual debiéramos los españoles relegar al último plano de nuestras preocupaciones cuanto

2 Cfr. FERRATER MORA, José, «Ortega y Gasset: etapas de una filosofia», in Obras Selectas, Tomo I, Madrid: Revista de Occidente, 1967, pp. 117-188.

3 Cfr. MÓRON ARROYO, Ciriaco, El sistema de Ortega y Gasset, Madrid: Ediciones Alcalá, 1968. A dificuldade em determinar com precisão a data do começo do primeiro estádio de evolução do pensamento de Ortega é referida pelo autor em ibid., p. 77; e a não correspondência com a apresentada pelo mesmo autor num outro texto seu, publicado dez anos depois, parece confirmar tal dificuldade - cfr. IDEM, Temas de investigación sobre la obra de Ortega, in «Los Ensayistas» - Boletín Informativo, Georgia (U.S.A.), Vol. III, n. ${ }^{\circ} 5$ (1978), p. 6. 
atañe a los individuos, a las personalidades; salvémonos en las cosas, sometámonos durante un siglo, cuando menos, a la severa e inequívoca disciplina de las cosas. Corrijamos el perfil deteriorado e incierto de nuestros ánimos según la pauta ofrecida por las líneas más quietas y más firmes de lo que se halla fuera de nosotros"'. Há relevantes razões biográficas subjacentes ao tom de incitamento nacional que Ortega usou em muitos dos seus discursos e artigos e que nomeadamente neste de 1908, Asamblea para el Progreso de las Ciencias, vem à tona. É evidente a expectativa de que, através de uma atitude filosófica anti-subjectivista, seria ultrapassável a indisciplina que era, na perspectiva de Ortega, um dos grandes obstáculos à afirmação positiva da sua pátria.

No auge da polémica em que se envolveu com Miguel de Unamuno, voltou a proclamar aquela atitude como antídoto eficaz da ausência de vigor e de responsabilidade intelectual em Espanha. "En el naufragio de la vida nacional escrevia então -, naufragio en el agua turbia de las pasiones, clavamos serenamente un grito nuevo: ¡Salvémonos en las cosas! La moral, la ciencia, el arte, la religión, la política, han dejado de ser para nosotros cuestiones personales (...)"7. Ortega mostra estar convicto de que, em virtude da sua formação, vencera o plano das questões pessoais, situando-se num nível do exercício intelectual mais adequado: era, afinal, o do conhecimento definido pelos neokantianos como válido e, portanto, o da Cultura.

No posicionamento orteguiano perante o programa regeneracionista de Joaquín Costa, vemos adiantarem-se um diagnóstico e uma terapêutica dos males nacionais que transcendem já as categorias do idealismo pós-kantiano da filosofia romântica. Esta pôs o acento nas diferenças, nas peculiaridades que se espelham espontaneamente nas criações humanas e na irredutível diversidade dos povos (que será o objecto por excelência das perspectivas historicistas). Ora, segundo Ortega, Joaquín Costa tinha assumido como indiscutiveis tais princípios e "creyó, consecuentemente, que la decencia nacional era un problema interior de la historia de España", "el resultado de la inadecuación entre la espontaneidad de la masa y la reflexión de la minoría gobernante", contra o que bastaria libertar "a aquélla de estas pegadizas influencias" e exigir: "vuélvase a la espontaneidad étnica, reconstitúyase la unidad espontánea de las reacciones castizas y España volverá a la ruta que un destino previo le ha designado"8. Ortega dirige aqui a sua análise para o primeiro dos dois pilares fundamentais do programa de Costa, o da reconstituição, que lhe parecia, em Março de 1911, ser contraditório com o segundo, a saber, o da europeização. A abertura de Espanha à Europa, que o pensador madrileno defendia desde há anos, justificando até a assimilação entre a Europa e a ciência ou "alta cultura", descartava, desde então, um nacionalismo confundido com casticismo 9 . Todavia, os efeitos dos seus estudos na Alemanha levam-no, inclusive, para lá dessa posição e manifestam-se, por exemplo, numa recusa de aspectos essenciais do idealismo de Schelling e Hegel em que, como sabemos, coincide em absoluto com a posição dos neokantianos. Essa recusa verifica-se na passagem seguinte de crítica às propostas de Joaquín Costa: "Siempre que releo aquel programa, me parece Costa el símbolo del pensador romántico, una profética fisionomía que ungida de fervor

4 Cfr. CEREZO GALÁN, Pedro, La voluntad de aventura - Aproximamiento critico al pensamiento de Ortega y Gasset, Barcelona: Ariel, 1984.

5 ORTEGA Y GASSET, José, Sobre los estudios clásicos, in O.C., I, p. 65.

6 IDEM, Asamblea para el Progreso de las Ciencias, in ibid., p. 102.

7 IDEM, Unamuno y Europa, fábula, in ibid., pp. 131-132.

8 Cfr. IDEM, Observaciones, in ibid., pp. 167-168.

9 Cfr., ex., IDEM, Pidiendo una biblioteca, in ibid., pp. 81-85; IDEM, Asamblea para el Progreso de las Ciencias, op. cit., pp. 99-110. 
histórico místico conjura sobre la ancha tierra patria el espíritu popular, el Volksgeist que pensaron Schelling y Hegel, el alma de la raza sumida en un sopor, cuatro veces centenario. Y claro está, no acudió, porque el espíritu popular no existe más que en los libros de una filosofía superada, supuesto que fuera alguna vez bien entendido" 10 .

Para além dos aspectos textuais que indiciam influências da escola marburguiana, contamos ainda com o reconhecimento explícito e inequívoco a ela dirigido pelo filósofo de Madrid, que diversas vezes a evoca na riqueza que simboliza, tanto a nível do seu desenvolvimento pessoal, como mais estritamente a nível filosófico. É o que Ortega condensa em três linhas - muito citadas, apesar de nem sempre aferidas pelo todo da sua obra: "En esta ciudad he pasado yo el equinocio de mi juventud; a ella debo la mitad, por lo menos, de mis esperanzas y casi toda mi disciplina. Ese pueblo es Marburg, de la ribera del Lahn"'l.

\section{Referências críticas à Escola de Marburg}

Como Nelson R. Orringer procurou demonstrar ${ }^{12}$, a marca dos mestres neokantianos Cohen e Natorp está patente em várias doutrinas orteguianas. No entanto, julgamos que, revelando-se nalguns momentos da sua obra um discípulo daqueles seus dois professores alemães, Ortega jamais foi um fiel seguidor do neokantismo que eles representam. Parecem-nos, por isso, verazes os seus próprios registos, em que enaltece a escola que se esforça por salvar a Filosofia das limitações que positivistas e irracionalistas lhe vinham impondo e, ao mesmo tempo, em que expõe os motivos pelos quais ela nunca the pareceu cabalmente satisfatória.

De certo modo, essa leitura de Ortega é mediada pelas suas referências a Cohen. Por um lado, afirma: "El gobernador de la ciudadela, Cohen, era una mente poderosísima. La filosofía alemana y la de todo el mundo tiene una gran deuda con él. Porque él fue quien obligó con un empellón, sin duda un poco violento, a elevar el nivel de la filosofia. Lo cual fue decisivo porque, más que todo en la vida, la filosofía es nivel. Cohen obligó a tomar contacto íntimo con la filosofía difícil y, sobre todo, renovó la voluntad de sistema, que es lo específico de la inspiración filosófica"13. Por outro lado, escreve páginas depois no mesmo texto: "Hombre apasionado Cohen, la filosofía se había concentrado en él como la energía en un condensador (...). Cuando yo le oí, su elocuencia se había reducido ya a pura patética. Pero entiéndase bien, de la más exquisita clase. Era pura retórica, pero no mala retórica, linfática, fofa y sin verdad íntima. Todo lo contrario. Su frase era, para ser alemana, anormalmente breve, puro nervio y músculo operante, súbito puñatazo de boxeador. Yo sentía cada una de ellas como un golpe en la nuca"14. É certo que Ortega contactou com Cohen de modo mais próximo em 1911, quando este estava a elaborar a última parte do seu System der Philosophie ${ }^{15}$, pouco antes de se transferir para a Universidade de Berlin já reconhecido como a figura nuclear do neokantismo de Marburg. Contudo, o comentário de Ortega ao ensino do professor alemão não se justificava apenas, nem pela sua idade avançada, nem pela

10 IDEM, Observaciones, op. cit., p. 169.

$"$ IDEM, Meditación del Escorial, in O. C., II, pp. 558-559.

12 Cfr. ORRINGER, Nelson R., Ortega y sus fuentes germánicas, Madrid: Editorial Gredos, 1979, capp. I e II.

13 ORTEGA Y GASSET, José, $P$. $A$., op. cit., p. 27. Para além do que na citação é referência expressa a Hermann Cohen, retenham-se dela também as afirmações orteguianas da filosofia como "nivel" e como "voluntad de sistema".

14 Ibid., p. 34.

15 Cfr. IDEM, Meditación del Escorial, op. cit., p. 559. 
sua idiossincrasia. Nos traços do seu trabalho revia-se a própria escola que ele integrava e se afigurava demasiado fechada ao jovem espanhol, sedento de ensinamentos seguros, mas também capazes de estimular novos empreendimentos filosóficos.

Quando foi para Marburg em Outubro de 1906, esta cidade era, como escreveu no Prólogo para alemanes, "el burgo del neokantismo", logo, o centro de uma das posições filosóficas que pontificavam no princípio do Século XX. Ortega relembra nestes termos a atmosfera em que aí se trabalhava: "Se vivía dentro de la filosofia neokantiana como en una ciudadela sitiada, en perpetuo: ¡Quién vive! Todo en torno era sentido como enemigo mortal: los positivistas y los psicologistas, Fichte, Schelling, Hegel. Se les consideraba tan hostiles que no se les leía. En Marburg se leía solo a Kant y, previamente traducidos al kantismo, a Platón, a Descartes, a Leibniz. Ciertamente que estos cuatro nombres son egregios, pero no es posible reducir todos los jugos de la Historia universal a menor número de gotas"16. Embora escritas em 1934, muitos anos depois da estada de Ortega em Marburg, estas palavras traduzem provavelmente uma apreciação decorrente da vivência de então.

Atentemos nos reparos principais feitos por Ortega. Em primeiro lugar, "en Marburg no se enseñaba filosofía. Era preciso saberla ya de antemano, traerla aprendida desde el vientre de la madre" 17 . Exemplo disso era o discurso de Cohen, cujas frases davam por suposto o conhecimento pelo ouvinte de algumas das ideias essenciais do seu pensamento ${ }^{18}$. Em segundo lugar, Ortega denuncia que "salvo aquella fertilísima voluntad de sistema, los neokantianos no disparaban las mentes jóvenes hacia problemas abiertos sobre que fuese posible e interesante trabajar. No se conocían más cuestiones que las resueltas ya en su canon"19. O nosso autor chega a estender esta crítica a todas as escolas neokantianas, considerando que elas se caracterizaram em geral por um "escaso repertorio de problemas, inquietudes y curiosidades" 20 . Neste contexto, Ortega refere-se à natureza de todas as atitudes que sejam "neo-algo", ou seja, que implicam um regresso a formas de vida inventadas no passado e que, por essa razão, ao serem readoptadas mais tarde, tornam inautênticos os que a elas recorrem em vez de encontrarem a sua própria forma de vida ${ }^{21}$. Porém, na situação histórica da filosofia europeia de meados do Século XIX viu Ortega a justificação da inevitabilidade de as duas gerações nascidas entre 1840 e 1870 serem "neo-algo". "En otros casos la inautenticidad es una culpa, pero en éste era un destino". E, apreciativamente, acrescenta: "Lo mejor que aquellos hombres podían ser era neokantianos", porque o hegelianismo tinha conduzido a uma catástrofe total da Filosofia, a uma espécie de "recaída en la infancia y el balbuceo intelectual" que obrigava a "volver a la escuela, es decir a los clásicos" 22 .

A geração anterior às dos neokantianos à qual pertenceram Wundt, Brentano e Dilthey, por exemplo, foi, segundo Ortega, "probablemente la más desdichada de toda la historia filosófica europea" ${ }^{23}$, uma vez que, não obstante as tendências novas que se insinuam nas doutrinas dos seus membros, ela não conseguiu, pela

16 IDEM, P.A., op. cit., p. 27.

17 Ibid.

18 Cfr. ibid., p. 34.

19 Ibid., p. 27.

20 Ibid., p. 28.

21 Cfr. ibid., pp. 28-29. A mesma concepção está também claramente expressa num artigo de 1924: cfr. IDEM, Las ideas de León Frobenius, in O. C., III, p. 253.

22 IDEM, P. A., op. cit., p. 29. Cfr. IDEM, La idea de principio en Leibniz y la evolución de la teoria deductiva, in O. C., VIII, p. 221.

23 IDEM, $P$. A., op. cit., p. 30. 
adversidade da sua circunstância fundamentalmente positivista, identificar e desenvolver as suas próprias potencialidades filosóficas. Quanto ao regresso dos neokantianos a uma filosofia que permitia retomar a técnica do pensamento entretanto perdida, era consequência de uma carência, que os continuava a impedir de atender àquelas novas tendências entrevistas nos autores imediatamente precedentes. Por seu turno, Ortega pertencia já a uma outra geração - talvez possamos chamar-lhe pós-neokantiana -, que, como dá conta no prólogo de 1934, tem maior afinidade com a de Brentano e Dilthey do que com a dos seus mestres neokantianos ${ }^{24}$. "El grupo de jóvenes que entre 1907 y 1911 aprendía en la ciudad del neokantismo los usos de la milicia filosófica, al llegar a los veintiséis años fecha que suele ser decisiva en la carrera vital del pensador - no era ya neokantiano"25. Ortega não deixa, todavia, de sublinhar com insistência o significado decisivo, na história da filosofia, do regresso aos clássicos, particularmente a Kant, e o valor exemplar de Cohen, a cuja obra e personalidade ${ }^{26}$ dirige elogios suficientes para reforçar a nossa compreensão de como à sua volta se foi edificando uma das escolas que, a par dos neokantianos de Baden (Windelband, Rickert, Jonas Cohn, Münsterberg), os realistas críticos e os empiriocriticistas, viria a representar a filosofia alemã vigente nos começos do Século XX.

Apesar disso, na transição para este século, é igualmente na Alemanha que mais se exprime a necessidade de uma Lebensphilosophie, de acordo com projectos filosóficos inspirados por autores tão diversos como Schopenhauer, Nietzsche, Simmel, Bergson, William James, Keyserling, ou Unamuno. E, por outro lado, Brentano, com a sua tendência favorável à observação e análise rigorosa dos fenómenos no âmbito da Psicologia, significa uma variante de trabalho profícua, comprovada pelos resultados do empenho com que a potenciaram Meinong, von Ehrenfels, Kraus, Husserl. Essas alternativas de pensamento, ainda que sem a força das posições que tinham retomado a problemática e as aquisições kantianas, estão presentes no contexto filosófico europeu mais poderoso nos períodos em que Ortega esteve na Alemanha. Porventura por isso, os jovens de então pressentiam algo, que formula nestas palavras: "Las filosofías [neokantianas] o próximas a ellas, únicas vigentes entonces, nos producían un estraño efecto que no nos atrevíamos a confesarnos: nos parecían... forzadas. (...) nos parecían profundas, serias, agudas, llenas de verdades y, no obstante, sin veracidad. (...). Nuestra impresión era, pues, que el pensamiento no se movía por dentro de aquellos sistemas holgadamente y

24 "Si el lector se ocupa algo de filosofía, advertirá, con sorpresa, que nuestro pensamiento actual vive de esas tendencias radicales, es decir, que esa generación es la que está más cerca de nosotros, esa y no las siguientes, temporalmente más próximas. Porque no será necesario hacer notar que nuestra filosofia tenía que ser llamada, en la perspectiva de 1870, psicologia". - Ibid., p. 32.

25 Ibid.

26 Para além das referências a Cohen no Prólogo para alemanes, anteriormente exemplificadas, encontram-se sobretudo nas cartas escritas pelo jovem Ortega de Marburg muitas outras, entre as quais esta reveladora de admiração e carinho: "Ayer salí a dar un paseo a la hora de ponerse el sol; me encontré con el Prof. Cohen y su señora y los acompañé a su casa: Cohen es grueso, pequeño, su figura es muy semejante a la de Renan; tiene una melena muy blanca y un hermoso perfil judio; habla de las cosas con esa sobria finura de los grandes sabidores y me abraza en arrebato cada vez que yo le nombro un libro judío-español o un tratado árabe. Me pregunta cosas de mi tierra y de su historia con una curiosidad inagotable. También él es cosmopolita a fuer de buen judio; en primavera suele irse siempre a Roma. En julio piensa ir a París y Londres y acaso la primavera que viene vaya a España". - IDEM, Cartas de un joven español (1891-1908), Madrid: Ediciones El Arquero, 1991, 179 (III), pp. 563-564. 
con satisfacción, entregado solo a la elasticidad de sus estrictas evidencias."27 Procurando clarificar esta impressão, assevera que havia muito de "ortopedia en aquel estilo de pensar. Se tomaba un autor o una ciencia - Descartes o la matemática o la jurisprudencia - y se le obligaba a decir velis nolis lo que previamente se había resuelto que dijesen" 28 .

No encadeamento daquele juízo encontramos, no precioso Prólogo para alemanes, uma referência irónica ao segundo grande nome da Escola de Marburg de quem Ortega também foi discípulo: "El caso de Natorp con respecto a Platón es ejemplar e increíble. Este Natorp, que era un hombre buenísimo, sencillo, tierno, con un alma de tórtola y una melena de Robinson Crusoe, cometió la crueldad de tener doce o catorce años a Platón encerrado en una mazmorra, tratándolo a pan y agua, sometiéndole a los mayores tormentos para obligarle a declarar que él, Platón, había dicho exactamente lo mismo que Natorp"29. Por uma carta enviada de Marburg a Unamuno em Janeiro de 1907, sabemos que o jovem Ortega reduzia na altura a indiscutível originalidade de Natorp a "originalidad técnica, (...) de interpretación y de crítica", embora o mencionasse como um "hombre de grandísima agudeza" Talvez subsista, no texto de quase trinta anos depois, um pouco dessa primeira apreciação de Natorp que, quando comparada com as referências a Cohen, parece ser uma depreciação ${ }^{31}$. Não esqueçamos, no entanto, que o que há de valoração negativa nos parágrafos que temos estado a analisar se dirige globalmente ao neokantismo, nomeadamente, às insuficiências que, segundo Ortega, nele descobriam os membros da sua geração. Aliás, o pensador madrileno acaba por radicar a falta de veracidade apontada aos neokantianos em geral no idealismo pós-kantiano de Fichte, Schelling e Hegel, considerando que se por um lado nestes autores "la filosofía encuentra por vez primera con toda plenitud su forma intelectual", por outro parecia que eles "sobornaban a la realidad para que aceptase el yugo de su doctrina" 32 . Os idealistas pós-kantianos estavam "decididos a conquistar el reino de un sistema, fuera como fuera" 33 e os neokantianos, a despeito da sua aversão a Schelling e a Hegel, procuraram - "sin saberlo", suspeita Ortega - elevar o kantismo ao nível do idealismo posterior de que teriam herdado "la insuficiente escrupulosidad y el excesivo afán de tener la razón"34.

Não nos deteremos na crítica orteguiana ao habitualmente designado idealismo alemão, mas interessa-nos ainda a síntese em que, no contexto que temos vindo a citar, Ortega enumera as razões do afastamento do que chama o "grupo juvenil de 1911" de todo o idealismo, mesmo o neokantiano. Refere como principal aspecto da reacção característica desse grupo a resolução de veracidade, isto é, "de someter estrictamente la idea a lo que se presenta como real, sin añadiduras ni redondeos". O segundo aspecto registado é a vontade de sistema e Ortega esclarece

Cfr. Epistolario completo Ortega - Unamuno, Madrid: Ediciones El Arquero, 1987, Carta X-Marburg, 27.I.1907.

31. Isso acentua Julián Marías na sua obra Ortega. Circunstancia y vocación quando escreve a respeito de Natorp: "Tenia mucho menor empuje que Cohen; unía a un gran saber un decidido espíritu de escuela, que imponía a todo sistema los esquemas neokantianos. Ortega se referió a esto "con buen humor» (...)". 2 MARÍAS, Julián, Ortega. Circunstancia y vocación, in Obras, tomo IX, Madrid: Revista de Occidente, [1982], pp. 346-347. (Essa última referência foi a que precisamente ilustrámos, há momentos, no corpo do trabalho).
Ibid., p. 38.

Ibid., p. 40. 
que "mientras los románticos apetecen el sistema como una delicia, por lo que tiene de fruto maduro, rotundo, dulce y rezumante, a nosotros se nos presentaba como la dura obligación específica del filósofo". No último ponto da enumeração, o autor diz que, a par destas posições de carácter formal, havia naqueles jovens em que ele se incluía "la convicción de que era preciso echar la nave al agua y abandonar no solo la provincia del idealismo romántico, sino todo el continente idealista" 35 .

\section{Adán en el Paraíso e o despontar de uma identidade filosófica}

Se é verdade que antes de 1905 Ortega tinha um conhecimento escasso do pensamento alemão - exceptuando Nietzsche, por ele citado desde o seu primeiro artigo $^{36}$-, a sua formação intelectual e académica inicial foi sólida e nela entroncou a investigação realizada posteriormente. Nos dois períodos de estudo em universidades alemãs, o pensador espanhol, doutorado em "Filosofía y Letras" e, no último deles, catedrático de Metafísica na Universidade Central, aproveitou para ler muitos livros, que o ajudaram a configurar uma ideia precisa do panorama da produção europeia que na altura não era acessível em Espanha ${ }^{37}$. Ortega estava, pois, habilitado para formular o seu juízo crítico em relação à ortodoxia neokantiana que encontrou em Marburg.

Já em 1910, no ensaio Adán en el Paraiso ${ }^{38}$, em que é notória a influência da estética de Hermann Cohen, o nosso autor nega-se a seguir estritamente as concepções em que se inspira. Atesta-o Nelson Orringer, que confronta cada passo desse ensaio com o tratado Kants Begründung der Aesthetik, escrito por Cohen em 1889, tendo de admitir que, a despeito das semelhanças nas respectivas estruturas, na concepção da arte e mesmo nalguns exemplos a que recorrem, o escrito de Ortega sintetiza doutrinas do mestre de Marburg de uma forma inovadora, insustentável no pensamento originário ${ }^{39}$.

35 Cfr. ibid., p. 41.

36 Cfr. IDEM, Glosas, in O. C., I, p. 16. Cfr. IDEM, Canto a los muertos, a los deberes y a los ideales, in ibid., p. 62. Cfr. o lugar de Nietzsche nos diálogos de Ortega com a sua personagem fictícia, Rubín de Cendoya: IDEM, «La pedagogía del paisaje», in Moralejas, in O. C., I, p. 56; IDEM, Teoría del clasicismo, in ibid., p. 74. O autor alemão de Also sprach Zarathustra foi um dos fortes elos da relação juvenil entre Ortega y Ramiro de Maeztu evocado pelo primeiro, aquando da polémica entre os dois - cfr. IDEM, ¿Hombres o ideas?, in ibid., p. 441. A apreciação mais directa do valor de Nietzsche na sua formação é feita por Ortega em El sobrehombre, artigo publicado no "El Imparcial» de 13.VII.1908 e que inicia com este parágrafo: "Todos los que no siendo actualmente demasiado viejos nos hemos dejado llevar desde la niñez a un comercio superfluo y tenaz con las cosas del espíritu encontramos en el recuerdo de nuestros dieciocho años una atmosfera caliginosa y como un sol africano que nos tostó las paredes de la morada interior. Fue aquella nuestra época de «nietzscheanos»; atravesábamos a la sazón, jocundamente cargados con los odrecillos olorosos de nuestra juventud, la zona tórrida de Nietzsche. Luego hemos arribado a regiones de más suave y fecundo clima, donde nos hemos refrigerado el torrefacto espíritu con aguas de alguna perenne fontana clásica, y sólo nos queda de aquella comarca ideal recorrida, toda arena ardiente y viento de fuego, la remembranza de un calor insoportable e injustificado". - IDEM, El sobrehombre, in O. C., I, p. 91.

(egista peremptoriamente que "Ortega fue a Alemania, en gran parte, a leer nueve o diez horas diarias, a absorber millares de libros que en España no se podían encontrar". - MARÍAS, Julián, Ortega. Circunstancia y vocación, op. cit., p. 341. ORTEGA Y GASSET, José, Adán en el Paraiso, in O. C., I, pp. 473-493. Citaremos, doravante, este artigo através da abreviatura $A$. $P$. 
Assim que se começa a analisar o conteúdo de Adán en el Paraiso, torna-se evidente a preocupação com a cultura espanhola que serve de enquadramento à reflexão estética aí desenvolvida. As considerações de Ortega sobre a arte, em particular sobre a pintura, partem das obras de Zuloaga que lhe parece colocarem os seus apreciadores de imediato perante a interrogação "¿Es asi España o no es así?"40 Por outras palavras, os quadros do pintor basco forçam-nos a transitar para uma realidade que transcende os elementos neles contidos e que comprova que "Zuloaga no concluye donde su pintura acaba"41. Ortega distingue num quadro dois planos: o das pinceladas, das linhas e das cores em que se transcrevem as coisas do mundo exterior; e o do que é verdadeira criação e apenas tem vida no interior do quadro. No primeiro temos algo de real; no segundo, algo puramente virtual que assegura ao quadro unidade. O que parece fácil afirmar, desde logo, é que, num quadro, cor e linha são coisas, ao passo que a unidade referida não. Em seguida, Ortega pergunta o que é uma coisa? - não tanto para esclarecer a afirmação anterior, como para salientar uma dificuldade específica da pintura. "Cada cosa es un pedazo de otra mayor - responde -, hace referencia a las demás cosas, es lo que es merced a las limitaciones y confines que éstas le imponen. Cada cosa es una relación entre varias" 42 .

Então, para pintar uma coisa é necessário começar por averiguar a sua relação com as restantes, o que, para além de ser difícil, conduz a diferentes resultados consoante o ponto de vista do pintor. Tem interesse verificar que Ortega não confina à pintura esta sua referência ao vínculo entre a realidade e o ponto de vista ou a perspectiva vital que a constitui. "Compárese lo que es la tierra para un labriego y para un astrónomo - sugere a título de exemplo - al labriego le basta con pisar la rojiza piel del planeta y arañarla con el arado; su tierra es un camino, unos surcos y una mies. El astrónomo necesita determinar exactamente el lugar que ocupa el globo en cada instante dentro de la enorme suposición del espacio sidéreo: el punto de vista de la exactitud le obliga a convertirla en una abstracción matemática, en un caso de la gravitación universal" ${ }^{43}$. Em suma, a situação ou modo de vida de cada um desses dois homens determina a sua perspectiva de uma coisa, da realidade, o que leva Ortega à conclusão de que não existe "esa suposta realidad inmutable y única con quien poder comparar los contenidos de las obras artísticas: hay tantas realidades como puntos de vista." E remata: "El punto de vista crea el panorama"44. $\mathrm{O}$ alcance desta asserção supera em muito a meditação sobre a arte pictórica que Adán en el Paraíso visava e julgamos assomar nela a teoria orteguiana da realidade e da verdade. Ou seja, mal tinha iniciado o ensaio, cujo tema de ordem estética é abordado com os propósitos do sistematismo kantiano e mediante uma terminologia neokantiana, Ortega afasta-se a um tempo da concepção tradicional de coisa como substância, da coisa em si que Kant distingue do fenómeno e do ser que na concepção de Cohen é uma ideia do pensamento construída por este, ao longo da história da ciência, como um problema.

Na continuação, o texto não faz senão confirmá-lo. Progressivamente vão-se esbatendo as tendências objectivistas e a busca da "unidade" ou do "ideal" distintivo da pintura impele Ortega, por um lado, a destacar a especificidade de toda a arte em relação à ciência e à moral - enquanto nestas "el concepto es soberano: es él la ley, construye él las cosas", na arte "su papel es meramente de guía, de

40 ORTEGA Y GASSET, José, $A$. P., op. cit., p. 474.

41 Ibid.

42 Ibid., pp. 474-475.

43 Ibid., p. 475.

44 Ibid.

${ }^{45}$ Cfr. ibid., p. 478. 
orientador" ${ }^{45}$; por outro, a radicar cada tipo de arte numa faceta da carêncią de expressão constitutiva do ser humano. O raciocínio de Ortega vai remeter-nos, rapidamente, do peculiar ideal de uma arte (dizendo-nos que ele está para ela como um órgão para uma dada função) para a necessidade que cria essa arte e, em última instância, para o problema que está na base de tal necessidade. E é o homem o lugar desse primordial problema. "El hombre lleva dentro de sí un problema heroico, trágico: cuanto hace, sus actividades todas, no son sino funciones de ese problema, pasos que da para resolver ese problema"46.

O valor metafórico do título do ensaio só a partir do quinto dos dezassete capítulos se desvela. Dado que nem a pedra nem o animal se dão conta de que vivem, Adão é o primeiro ser que, feito à imagem de Deus, tem capacidade, tanto de viver, como de se sentir viver ${ }^{47}$. Por isso, Ortega reconhece na criação do primeiro homem significado universal. "El suceso fue de enorme trascendencia: el hombre nació y súbitamente sonaron sones y ruidos inmensos a lo ancho del universo, iluminaron luces los ámbitos, se llenó el mundo de olores y sabores, de alegrías y sufrimientos. En una palabra, cuando nació el hombre, cuando empezó a vivir, comenzó asimismo la vida universal"48. Esta ideia torna-se ainda mais precisa: "Cuando Adán apareció en el Paraíso (...) comenzó a existir esto que llamamos vida". Trata-se, portanto, da vida humana; desde logo, da vida humana como problema, porque para Adão "la vida existe como un problema" 49 e mesmo o homem é o proble$m a$ da vida ${ }^{50}$. O título do ensaio é, afinal, a metáfora para este ser inconfundível, o ser humano, que não se limita a viver, mas antes, como Adão no Paraíso, ao sentir-se viver "es la pura y simple vida, es el débil suporte del problema infinito de la vida" 51 .

Ortega aproxima-se cada vez mais da intuição fundamental da sua filosofia. Indubitavelmente conhecedor da teoria de Cohen da vida individual como problema da realização da Ideia de si mesmo, o pensador madrileno dá novos contornos à concepção da problematicidade da vida ${ }^{32}$. A ciência, a moral e a arte são postas na dependência da vida humana. Compaginando as influências neokantianas recebidas e a novidade que irrompe no seu discurso, afirma que o problema que o homem leva dentro de si é tal, que tudo o que faz fá-lo na tentativa de o resolver ${ }^{53} \mathrm{e}$, seguindo a máxima divide et impera, "el hombre lo secciona y lo va resolviendo por partes y estadios. La ciencia es la solución del primer estadio del problema; la moral es la solución del segundo. El arte es el ensayo para resolver el último rincón del problema"s4. Esta citaçã̃o iluštra bem que, conforme Orringer sumariou, enquanto Cohen parte da fundamentação da Cultura como solução do problema da vida

46 Ibid.

47 Cfr. ibid., pp. 479-480.

48 Ibid., p. 480.

49 Ibid.

so Cfr. ibid., pp. 480-481.

s1 Cfr. ibid., p. 480.

52 Rodríguez Huéscar, analisando o primeiro atributo da vida que se nos revela em Adán en el Paraiso, a saber, a sua estrutura problemática que faz com que a vida não apenas tenha problemas, mas também consista num problema, considera que a filosofia de Ortega a partir desse momento "no va a ser, en su dimensión más genuina y profunda, otra cosa que la lucha por la posesión intelectual, el despliegue conceptual de esta idea. La problematicidad - sustenta - va a figurar entre las categorías metafísicas primarias. En torno a ellas vamos a ver articularse gran parte de las demás (...)". - RODRÍGUEZ HUÉSCAR, Antonio, Perspectiva y verdad, Madrid: Alianza Editorial, 1985, pp. 51-52.

53 Cfr. n. 46.

54 Ibid., p. 479. 
individual, Ortega parte, num intuito sistemático, do próprio problema ${ }^{55}$. Pode até considerar-se Adán en el Paraíso um inicial esforço orteguiano de circunscrição desse problema em que a vida humana consiste; é já, portanto, um ensaio filosófico a seu respeito, apontando limites à noção de vida em termos puramente biológicos ${ }^{56}$ e perseguindo "un concepto de vida más general, pero más metódico" 57 . Apesar de tudo, a meditação desencadeada é de inspiração idealista, sendo a vida de uma coisa definida como uma encruzilhada de relações, de influências mútuas em que todas as outras coisas do Universo estão co-implicadas. Ortega, marcado, quer pela terminologia, quer pelas doutrinas neokantianas, recorre ao sistema planetário como exemplo de um sistema de movimentos e de relações, no seio do qual se determina o ser de cada planeta. A Terra é, assim, possível, em virtude dos demais planetas do mesmo sistema, e o inverso é igualmente verdadeiro, porquanto todos são elementos em relação mútua. E o autor conclui: "Según esto, la esencia de cada cosa se resuelve en puras relaciones" ${ }^{58}$.

Há algo de contraditório entre essa posição e a concepção perspectivista da realidade que Ortega tinha esboçado anteriormente ${ }^{59}$. Ele mesmo reage, numa nota de 1915, ao momento do texto em que, em abono daquela conclusão, escrevia que "[u]na piedra al borde de un camino necesita para existir del resto del Universo"60. Regista nessa nota: "Este concepto leibniziano y kantiano del ser de las cosas me irrita ahora un poco" $"$. Contudo, em Adán en el Paraíso afloram muitas ideias desenvolvidas por Ortega na sua obra mais madura. Em 1910, a par de frases que denunciam proximidade aos filósofos marburguianos, encontram-se aquelas em que deles se demarca, como quando aponta limites aos conceitos científicos, que para eles eram nada menos que os construtores da realidade.

Também o método do conhecimento se revela problemático, à medida que 0 problema da vida se impõe à meditação. A vida a investigar não se esgota no estudo biológico, nem em nenhum estudo que procure apenas o geral, a lei. Se tivermos presente a peculiar preocupação com Espanha que ocupou lugar decisivo em todas as decisões de Ortega - entre as quais a de ir à Alemanha em busca de alimento intelectual que lhe permitisse elaborar uma proposta pessoal de saída para as questões integrantes dessa preocupação -, entenderemos que, por mais empolgante que fosse a descoberta do rigor sistemático dos neokantianos, este não the bastaria. Em posse da respectiva disciplina mental, usaria esta sempre como meio para a compreensão do que se lhe afigurava problemático; se no ensaio de 1910 um tema da pintura o conduz irremediavelmente à vida como problema, é por este que tem de avaliar todo o aprendido. Ora, a ciência, adianta Ortega, "se afana por descubrir ese ser inagotable que constituye la vitalidad de cada cosa. Pero el método que emplea compra la exactitud a costa de no lograr nunca del todo su empeño". O que subsiste como desconhecido, ao escapar à abstracção, é o individual, o concreto, o vital. "La ciencia - escreve em seguida - nos ofrece sólo leyes, es decir,

s5 Cfr. ORRINGER, Nelson R., Ortega y sus fuentes germánicas, op. cit., p. 56.

56 "La ciencia parece reduzir el significado de la palabra vida a una disciplina particular: la biología. Según esto, la matemática, la física, la química, no se ocupan de la vida (...)”. ORTEGA Y GASSET, José, $A$. P., op. cit., p. 481.

57 Ibid.

58 Ibid.

59 Ortega volta, inclusive, a evocar, mais tarde no texto, a concepção perspectivista, dando como sabido que "cada par de ojos ve una cosa distinta" - ibid., p. 486.

60 Ibid., p. 482. Encontramos ao longo do texto outras frases baseadas na mesma tese, ex., "(...) un individuo, sea cosa o persona, es el resultado del resto total del mundo: es la totalidad de las relaciones"; "En el nacimiento de una brizna de hierba colabora todo el universo". - Ibid., p. 484. 
afirmaciones sobre lo que las cosas son en general, sobre lo que tienen de común unas con las otras, sobre aquellas relaciones entre ellas que son idénticas (...)"62.

O exemplo a que recorre, para sublinhar o que para a ciência é inalcançável, é extraordinariamente significativo. "¿Qué es esta piedra venerable del Guadarrama? Para la ciencia esta piedra es un caso particular de una ley general. La ciencia convierte cada cosa en un caso, es decir, en aquello que es común a esta cosa con

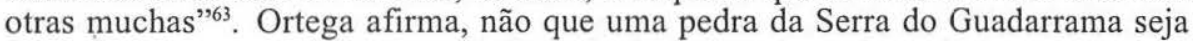
um caso entre outros que uma lei geral abarca, e sim - isso destaca-se no seu discurso - que para a ciência aquela pedra é apenas o que são quaisquer outras pedras. Como poderia ele - grande apreciador da Serra que é horizonte para Madrid e para os quadros de Velázquez - conformar-se com essa indistinção imposta pela abstracção científica? A pedra do Guadarrama não é só uma entre outras quimicamente idênticas, tal como, por exemplo, Napoleão não é só um entre outros seres da espécie humana - diz-nos, requerendo que "las cosas sean algo más que cosas" e postulando que "la vida es lo individual" 64 .

Só agora Ortega pode retomar a sua reflexão sobre a arte, uma vez que o problema desta é o vital, o concreto, o único, ou seja, o que escapa à ciência ${ }^{65}$. Sem pôr em causa a concepção da natureza como o que acontece segundo as leis da fisica, contrapõe-lhe a da vida como o absolutamente passageiro e inventaria alguns dos vectores da difícil missão artística. $\mathrm{O}$ artista procura, não a materialidade da vida de cada coisa, mas a ficção da sua totalidade e, por esse caminho, assume a tarefa de refundir na forma estética, quer o material, quer o emocional. Por isso é que, na sua obra de arte, cria uma realidade aí individualizada para sempre ${ }^{66}$. Ortega atribui à pintura, em especial, a finalidade de interpretar o problema da vida na sua multiplicidade de co-relações ${ }^{67}$ e traça uma comparação entre essa arte plástica e a novela.

Neste intento de compreensão da proximidade ou distância do pensador espanhol à escola neokantiana de Marburg vale a pena, por fim, acentuar como Adán en el Paraíso culmina na expressão orteguiana da necessidade de pensar, de uma forma sistemática, a tragédia imensa do viver ${ }^{68}$. O percurso da reflexão estética no ensaio é claro: interessado pela origem das emoções que nele despertaram os quadros de Zuloaga, Ortega quer saber a quem deve chamar-se pintor, o que deve este pintar; considerando que o objecto de um pintor são as coisas e estas são apenas relações, pergunta pelas relações que serão essencialmente pictóricas; e conclui que estas são as que reflectem a vitalidade na sua forma espacial ${ }^{69}$ ou, brevemente, "lo pintado ha de ser vida" enriquecido por uma singular meditação, em que a metáfora de Adão no Paraíso serve ao mesmo tempo de resposta para a questão estética e de símbolo da vida humana. Esta era já o principal problema para o jovem filósofo que, devedor aos neokantianos pela sua lição de rigor filosófico, destes se afastará doravante cada vez mais.

Ibid., p. 482.

Ibid.

Ibid.

Cfr. ibid., p. 483.

Cfr. ibid., pp. 483-487.

Cfr. ibid., p. 487 e p. 491.

Cfr. ibid., p. 493.

Cfr. ibid., p. 489.

Ibid., p. 491. 


\section{A intuição e a vivência como agulhas de um novo marear}

Regressemos à referência de Ortega ao "grupo juvenil" que em 1911, em Marburg, se sente convicto de que era preciso lançar a nave à água e abandonar todo o continente idealista ${ }^{71}$. Reassumindo essa convicção compartilhada, sustenta que se tratava ainda de remar em direcção a uma costa imaginária e, de imediato, acrescenta: "Sin embargo, la fortuna nos habia regalado un prodigioso instrumento: la fenomenologia":72. Instrumento, para quê? Desde logo - compreende-se em vista do contexto -, para identificar limites do idealismo até aí meramente pressentidos.

A acreditar no próprio Ortega, o seu estudo a sério da fenomenologia começou em $1912^{73}$. Alude à fenomenologia anunciada por Edmund Husserl, na sua obra Logische Untersuchungen (1900-1901), como, acima de tudo, um método de análise intencional, que visa chegar à autêntica relação entre o objecto conhecido e o eu que o conhece. A que viria a revelar-se uma das correntes filosóficas mais decisivas do Século XX terá marcado Ortega desde os contactos iniciais, pelo que em 1913 - o próprio ano da publicação do primeiro dos doze volumes do Jahrbuch für Philosophie und phänomenologische Forschung - dedica à fenomenologia o discurso intitulado Sensación, construcción e intuición ${ }^{74}$ e os escritos, que a «Revista de Libros» publicou entre Junho e Setembro, Sobre el concepto de sensación ${ }^{75}$.

O texto de Sensación, construcción e intuición, apresentado ao inaugurar-se uma Secção Filosófica na Asociación Española para el Progreso de las Ciencias, abre com um propósito adequado ao momento, o de partir do "problema mismo inicial de la filosofia, el problema que constituye sus umbrales"76. Para o esclarecer é necessário reflectir sobre a especificidade da Filosofia, disciplina que Ortega apresenta como responsável por provar todas as suas afirmações, incluindo as que fazem dela a ciência das teorias científicas. Embora seja notória a coincidência entre esta concepção orteguiana e o objectivo de Husserl de alcançar

71 Cfr. n. 35 .

72 Cfr. n. 1.

${ }^{73}$ Cfr. ibid., p. 47. É, no entanto, de crer - apesar de não ser fácil documentar o que leu em 1911 - que, durante a sua segunda estada em Marburg, Ortega se terá dedicado, como escreveu San Martín, "a saldar cuentas con el neokantismo y hacerse con la práctica del método fenomenológico". - SAN MARTÍN, Javier, "La fenomenología de Ortega», in AAVV, Ortega cien años despues - Homenaje a José Ortega y Gasset en la ciudad en la que cursó su bachillerato, Málaga: U.N.E.D. - Centro Asociado de Málaga, 1987, p. 105. (Texto republicado por J. San Martín com o título «La filosofia de Ortega y Gasset como fenomenologia», in Ensayos sobre Ortega, Madrid: UNED, 1994, cap. II). Também não é de desatender o conhecimento e a dada altura até proximidade à fenomenologia por parte de Natorp, com quem Ortega estudou Pedagogia durante a sua primeira estada na Alemanha. "Sabido es (...) que pocos de los que profesaban en Marburg sabían más que Natorp sobre la fenomenología. Había mantenido correspondencia con Husserl por lo menos desde,1894, y a la lógica y a la psicología de Natorp debía Husserl no poco de su pensamiento maduro. Ambos filósofos se respetaban mutuamente, y se complacían en señalar, cuando era posible, las semejanzas de sus doctrinas. [Iso Kern, Husserl und Kant: Eine Untersuchung über Husserls Verhältnis zu Kant und zum Neukantianismus, Martinus Nijhoff, La Haya, 1964, págs. 13 y 321-373. (...)]”ORRINGER, Nelson R., Ortega y sus fuentes germánicas, op. cit., p. 76.

74 Trata-se do discurso inaugural da Secção Filosófica da Asociación Española para el Progreso de las Ciencias proferido no IV Congresso desta associação e publicado, ainda em 1913, em Madrid. Cfr. ORTEGA Y GASSET, José, Sensación, construcción e intuición, in O. C., XII, pp. 487-499.

75 Cfr. IDEM, Sobre el concepto de sensación, in O. C., I, pp. 244-260.

76 IDEM, Sensación, construcción e intuición, op. cit., p. 487. 
uma filosofia fundamentadora, uma filosofia sem pressupostos, apenas orientada por evidências apodícticas, a sequência do discurso não nos mostra Ortega incondicionalmente rendido à fenomenologia. Se é certo que no final entrevemos uma expectativa positiva em relação à possibilidade de a intuição husserliana ultrapassar as dificuldades encontradas, tanto pelo empirismo radical de Mach e Ziehen, como pelo idealismo neokantiano, quanto ao problema do conhecimento, não é menos evidente que o nosso autor compreende a amplitude e a radicalidade da reforma que à Filosofia se impunha, obrigando a uma cuidadosa busca dos meios para a realizar. Pelo menos em parte, defende, a Filosofia é a teoria da teoria, pois, enquanto as restantes ciências supõem as condições constitutivas da teoria in genere e fundamentam apenas o que em cada uma delas há de particularização dessa teoria, ela não pode dar por supostas essas condições, na medida em que a sua forma de ciência coincide com o seu domínio, sendo de igual modo um problema seu. Pode até recorrer a suposições que depois prova por si mesma, ou em que o suposto não é dado como verdade provada por nenhuma outra ciência nem por qualquer faculdade que não seja sua; o que a Filosofia não admite é ter congenitamente carácter genérico de conhecimento verdadeiro, pelo contrário, assume como sua tarefa descobrir e justificar o critério que garanta a verdade dos juízos ou proposições que integram as suas teorias e toda a teoria ${ }^{77}$. Tendo então de "ganarse la vida desde la cuna"78, pode ser considerada a ciência sem supostos.

Por conseguinte, o problema radical da Filosofia é o de procurar uma função cognoscitiva que, pelas suas características intrínsecas, assegure ab initio aos seus conteúdos o valor de verdades. As funções cognoscitivas são funções de um sujeito, mas o seu correlato ou conteúdo genuíno poderia chamar-se ser, verdade, realidade ou objectividade. Uma função puramente receptiva do sujeito parece ser, à partida, a solução para o problema, porque o objecto seria conhecido de uma forma directa sem necessidade de qualquer representação intermédia. Segundo Ortega, era isso mesmo que o empirismo radical então preconizava, fazendo depender da sensação a possibilidade do conhecimento primordial e identificando o ser com o que é sentido, o conhecer com o sentir. Esta posição suscita-lhe um comentário irónico, por reduzir o ser humano a mera passividade ${ }^{79}$, e contra ela levanta uma objecção essencial, aliás aquela de que parte o idealismo para a sua concepção construtivista do conhecimento, a saber: o sentir puro postulado pelos empiristas só garantiria a objectividade pura do conteúdo das sensações, se também ele fosse encontrado pela mesma função cognoscitiva e não através da análise lógica e psico-fisiológica. Todavia, o que Mach chama elementos, como por exemplo o som, a luz, etc., não são propriamente dados, são resultados da ciência que, uma vez desvelados, continuam a não poder dispensar os processos científicos que a eles dão acesso. Portanto, os empiristas consideram sensações puras ou dados objectivos algo que não satisfaz o requisito de que haja uma relação imediata entre a função cognoscente originária e o ser.

Por seu turno, a posição idealista, baseada nessa infidelidade ou contradição, põe o problema nestes termos: "Si no hay ninguna función cognoscitiva real en que el ser llegue a nosotros sin deformación subjetiva; si no

77 Cfr. ibid., pp. 487-488.

78 Ibid., p. 489.

79 "Como manifestación de una época es - digámoslo al pasar - bastante sospechosa esta solución al problema máximo de la cultura. Nótese que en ella se busca el criterio, la esencia misma del saber, "supremo don del hombre» como Goethe cantaba, justo allí donde el hombre como agente desaparece (...). ¿No es sintomático de todo un ciclo de la civilización europea esta desconfianza hacia el hombre y esta intención de corregir y rectificar lo especificamente humano mediante lo infrahumano?" - Ibid., p. 490. 
hay modo alguno en que el objeto sea dado al sujeto tendremos, o que renunciar al conocimiento, o que transformar por completo los términos correlativos «ser» y "conocer»"80. Não renunciando ao conhecimento, Kant, que realiza a sua revolução copernicana no âmbito lógico, e os neokantianos, que dispensam de valor fáctico todos os actos cognoscitivos, optam decididamente pelo segundo membro da alternativa. A Filosofia afasta-se com eles da subordinação do conhecer ao ser própria do senso comum, afasta-se em particular do preconceito de que o conhecimento supõe uma relação de causalidade psico-física entre um sujeito e um objecto (o que faz depender a verdade lógica da verdade factual, ou mesmo a inviabiliza). "Afortunadamente va desapareciendo de la mente contemporánea este prejuicio, que es a la vez una contradicción" contexto, do papel positivo do idealismo científico, na história da discussão do grande problema da Filosofia. Denomina inclusive de aparente $^{82}$ a dificuldade proveniente de o idealismo neokantiano, ao levar ao extremo a inversão dos termos do problema já realizada por Kant, asseverar que o conhecimento é uma função ideal de resolução de problemas, uma construção a que a verdade, a realidade, a objectividade são imanentes. Sabemos que é desta forma que o neokantismo concebe o conhecimento à margem de toda a receptividade; o pensamento como capaz de se estruturar por si mesmo e no seu interior construir o ser como objecto ideal; e a Ciência, a Cultura, como o acervo de hipóteses, regras ou ideias, de acordo com as quais deverá actualizar-se o conhecimento válido.

Porém, Ortega regista duas dificuldades que a concepção construtivista do conhecimento enfrenta. A primeira consiste na necessidade de que a função cognoscitiva, como Hartmann aponta no seu Systematische Methode, parta sempre de um problema ${ }^{83}$. Para além de formular a questão que se coloca ao idealismo neokantiano, Ortega antecipa uma possibilidade de resposta: "Un problema no es simplemente la nada, es algo, contiene alguna determinación por simple y borrosa que ella sea", mas o idealismo "puede decir - ya Platón insistía sobremanera en ello - que los problemas nacen de soluciones previas a problemas más sencillos" A segunda dificuldade é que não será tão contornável pela teoria idealista do conhecimento: "¿basta con el carácter de construcción (...) para definir el conocimiento? ¿Es conocimiento sólo y esencialmente la determinación de los fenómenos según puntos de vista hipotéticos? En suma: aun reconociendo que la teoría sea una actuación, una generación de los objetos (...) ¿puede decirse que sea sólo eso?"»s.

Enunciada sob a forma de perguntas e pelo modo como Ortega desenvolve alguns aspectos por estas implicados, tal dificuldade parece ser autenticamente sentida. O filósofo espanhol, que evoca a categoria de consentimento de Leibniz na qual via a antecipação da unidade transcendental da apercepção de Kant e da unidade do pensar de $\mathrm{Cohen}^{86}$-, diz não ver possibilidade de o sujeito afirmar a coincidência entre os dois termos, cujo consentimento integra o conhecer, sem que eles estejam, de alguma forma, previamente presentes a esse sujeito ${ }^{87}$. E nem sequer essa coincid̂ência é uma construção; trata-se, sim, de algo de que o sujeito se apercebe. É precisamente neste patamar reflexivo de Ortega que a intuição

\footnotetext{
80 Ibid., p. 491.

81 Ibid., p. 494.

82 Cfr. ibid., pp. 493-494.

83 Cfr. ibid., p. 496.

84 Ibid.

85 Ibid., p. 497.

${ }^{86}$ Cfr. ibid., p. 496.

87 Cfr. ibid., p. 497.
} 
husserliana surge como hipótese para responder ao problema do conhecimento que nem o empirismo resolvia, por cair em contradição, nem o idealismo, pois "bien puede, en su totalidad, ser la función cognoscitiva una construcción del objeto; pero cada uno de los pasos o momentos de ella exige una simple intuición de los términos puestos en relación" 88 .

Que um juízo ou uma proposição supõem sempre a intuição, quer dos termos nele ou nela relacionados, quer da relação entre estes, antes mesmo de se pôr o problema propriamente do ser ou da verdade aí implicados, provam-no vários exemplos. Tomando o juizo " $a$ " é causa de " $b$ ", verifica-se ser precisa em mim a presença de "a" e "b", por um lado, e de "causalidade", por outro, com antecedência a tudo o mais. Sustentar isto é inconfundível, vinca Ortega, com a concepção, para ele inadmissível, do sujeito e do predicado do juizo como dois conceitos ou duas representações prévias; qualquer proposição do tipo um quadrado redondo é impossivel basta para demonstrar que, não sendo o quadrado redondo um conceito e menos ainda uma representação, algo tem de ser para o sujeito antes de ele poder exprimir a sua impossibilidade. Em suma, o que Ortega em 1913 defende, sem hesitações, é a importância, para esclarecer o problema primário da Filosofia, da intuição, isto é, "una función previa aun a aquella en que construimos el ser o el no ser"89. Embora admita não ver por enquanto com toda a nitidez os limites e a constituição da proposta de Husserl, em torno da qual se geravam então discussões muito variadas e profundas, a sua nota final ressuma máxima esperança: "Tal vez se abre con el principio de la intuición una nueva época de la filosofia"'90.

Os escritos Sobre el concepto de sensación ${ }^{91}$ reforçam a ideia de que Ortega conhecia na altura bastante da fenomenologia husserliana. Igualmente do ano em que foram publicadas as Ideen zu einer reinen Phänomenologie und phänomenologischen Philosophie, fazem a recensão da tese de doutoramento Untersuchungen über den Empfindungsbegriff de Heinrich Hoffmann. Estẹ discípulo de Husserl, para além de examinar diversas definições psicológicas de sensação nomeadamente as de Ebbinghaus, Hildebrand e Wundt -, pretende chegar no seu trabalho ao conceito fenomenológico da sensação. Tal objectivo de Hoffmann legitima que o nosso filósofo envolva a sua análise dos temas da dissertação no esclarecimento da fenomenologia como método. As vantagens deste mostram-se no contraste com a dedução e a indução, que levam a proposições cuja verdade procede, ou de outras dadas como provadas, ou de conceitos puramente lógicos estabelecidos como axiomas, mesmo quando essas proposições dizem respeito a objectos materiais. Tanto num caso como noutro, portanto, estamos perante métodos indirectos de obtenção de proposições verdadeiras e perante o abandono dos objectos nelas considerados ${ }^{2}$. Por seu lado, a fenomenologia explica a possibilidade de nos darmos conta, através da intuição, de estados objectivos individuais e de, por abstracção dos elementos espácio-temporais, transformar o que inicialmente era intuição individual em intuição essencial. Deste modo, a verdade das proposições não acarreta que se abdique dos objectos nelas referidos, na medida em que é viável libertá-los das notas individualizadoras da experiência em que se nos dão e, ao mesmo tempo, descrever o que eles são.

É digna de nota a clareza com que os vectores principais do método fenomenológico aparecem em Sobre el concepto de sensación, numa fase em que o próprio Husserl julga ainda extraordinariamente dificil compreender o sentido

88 Ibid..

89 Ibid., p. 498.

90 Ibid., p. 499.

91 Cfr. n. 75.

92 Cfr. ibid., pp. 249-251. 
peculiar dos problemas da fenomenologia ${ }^{93}$. Ortega, que cita a na altura recentíssima edição original de Ideen, sumaria as suas grandes teses: "Hay una «manera natural» de efectuar los actos de conciencia, cualesquiera que ellos sean. (...) la «postura natural» en el acto de percepción consiste en aceptar como existiendo en verdad delante de nosotros una cosa perteneciente a un ámbito de cosas que consideramos como efectivamente reales y llamamos «mundo». (...). A esta eficacia de los actos cuando nuestra conciencia los vive en su actitud natural y espontánea llamábamos el poder ejecutivo de aquéllos". Cremos ser devido alongar a citação: "Supongamos, ahora, que al punto de haber efectuado nuestra conciencia, por decirlo así, de buena $f e$, naturalmente, un acto de percepción se flexiona sobre sí misma, y en lugar de vivir en la contemplación del objeto sensible, se ocupa en contemplar su percepción misma. Esta con todas sus consecuencias ejecutivas, con toda su afirmación de que algo real hay ante ella, quedará, por decirlo así, en suspenso; su eficacia no

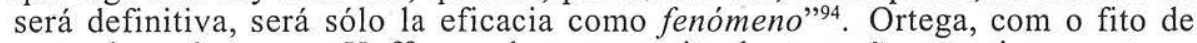
enquadrar a busca por Hoffmann de um conceito de sensação, mencionara antes a unidade, na consciência, de actos de diferente grau com uma relação funcional entre si, assinalando carácter básico ou fundamental aos actos que apresentam imediata e simplesmente objectos - actos apresentativos - mesmo quando eles são periféricos, ou seja, não constituem o eixo da nossa atenção ${ }^{95}$. Evidenciava assim "el complejo edificio de nuestra conciencia integral"96 e antecipava, de algum modo, o rigor exigido por uma análise da consciência. Agora, a distinção fenomenológica entre o plano dos actos perceptivos realizados na atitude natural da consciência e o plano em que esta se vira sobre si mesma para contemplar a percepção confirma essa direcção de rigor.

A consciência, na reflexão sobre a sua actividade perceptiva, nem a altera, nem a explica; suspende-a, coloca-a tão-somente entre parêntesis, permitindo passar da atitude natural à descrição pura dos actos de consciência e dos seus objectos. Por essa via, obtém-se o fenómeno entendido, não à maneira kantiana, como Ortega marca, mas enquanto "el carácter virtual que adquiere todo cuando de su valor ejecutivo natural se pasa a contemplarlo en una postura espectacular y descriptiva" ${ }^{97}$. A fenomenologia, metodologia e realização desta descrição, não pode ser confundida com a Psicologia, precisamente porque não se resume a estudar a consciência como um facto e analisa-a como consciência de algo, que nela se constitui como objecto; numa há lugar para a descrição empírica, noutra para uma descrição pura que nos remete para o plano de uma objectividade primária em que tudo é tomado conforme aparece (phainomenon) por redução fenomenológica. O lugar e a relevância da consciência de na teoria proposta por Husserl ressaltam num interessante exemplo: "El brillo metálico es esta patente peculiaridad luminosa que percibimos como envolviendo este objeto de plata. Un físico estudiará por qué combinaciones no patentes, inmanifiestas, se produce este fenómeno. El psicólogo estudiará por qué mecanismo psicofisiológico llegamos a esa percepción. El físico, pues, busca del lado de allá del fenómeno «brillo metálico» la constitución de la cosa material que en aquél se nos manifiesta. El psicólogo busca la génesis del

93 Cfr. HUSSERL, Edmund, Ideas relativas a una fenomenología pura y una filosofia fenomenológica, trad. do Alemão de José Gaos, 2. ${ }^{a}$ ed., México-Buenos Aires: Fondo de Cultura Económica, 1962, p. 9.

94 ORTEGA Y GASSET, José, Sobre el concepto de sensación, op. cit., p. 252.

95 Cfr. ibid., pp. 248-249.

96 Ibid., p. 249.

97 Ibid., p. 253. 
mismo en la realidad de una psique individual. Ambos, pues, parten del fenómeno y lo abandonan por (...) productos de una operación racional constructiva. Y el caso es que antes de todo esto hubiera convenido entenderse sobre qué sea el «brillo metálico» mismo - o de otro modo - qué clase de colores y en qué disposición, etc., tenemos que verlos para que, en efecto, veamos brillo metálico"98. Através de palavras tão sugestivas, Ortega afirma a necessidade primordial de fixar a essência dos fenómenos por mais vulgares que estes pareçam, como no exemplo dado ${ }^{99}, \mathrm{e}$, por outro lado, discrimina o que há de herdado e de novo na fenomenologia: já no idealismo clássico os objectos eram, em primeira instância, presenças imediatas na consciência; contudo, essa sua objectividade primária era depois circunscrita a uma determinada classe de objectos que acabava confundida com toda a realidade, ao passo que a fenomenologia procura manter-se no plano do vivido, no que ele tem de imediato e de patente, para aí descobrir descritivamente a realidade de que a consciência é consciência de.

A referência por Ortega à consciência (intencional) e à importância do plano das vivências, leva-o a introduzir uma longa nota que tem grande significado na filosofia propriamente orteguiana. $\mathrm{O}$ autor levanta nela o problema da sua tradução do termo alemão "Erlebnis" pelo espanhol "vivencia": "Esta palabra, "Erlebnis", fue introducida, según creo, por Dilthey. Después de darle muchas vueltas durante años esperando tropezar algún vocablo ya existente en nuestra lengua y suficientemente apto para transcribir aquélla, he tenido que desistir y buscar una nueva" ${ }^{100}$. A justificação que dá, no seguimento, é deveras emblemática. Em síntese, diz que "en frases como «vivir la vida», «vivir las cosas», adquiere el verbo «vivir» un curioso sentido. Sin dejar su valor de deponente toma una forma transitiva significando aquel género de relación inmediata en que entra o puede entrar el sujeto con ciertas objetividades. Pues bien, ¿cómo llamar a cada actualización de esta relación? Yo no encuentro otra palabra que «vivencia». Todo aquello que llega con tal inmediatez a mi yo que entra a formar parte de él es una vivencia. Como el cuerpo físico es una unidad de átomos, así es el yo (...) una unidad de vivencias"101. Aqui, o recurso a cada actualização da relação entre um sujeito e certos objectos para definir uma vivência, bem como a ideia de que essa relação faz parte do meu eu podem ser interpretados como esboços das formulações especificamente orteguianas, primeiro da vida como o que cada ser humano concretiza numa dada circunstância e, mais tarde, desta vida individual como a realidade radical ${ }^{102}$.

98 Ibid., p. 255.

99 Fixar o que seja o brilho metálico, que é o que vemos - enquanto e só enquanto o vemos -, parecerá simples e supérfluo, mas, diz Ortega, basta tentar defini-lo para se verificar como é uma "tarea sobremanera penosa. Probablemente no se ha dado todavía una descripción satisfactoria de cosa tan baladi. Si la hubiéramos a la mano poseeríamos la definición de la «conciencia de» brillo metálico (...)". - Ibid.

100 Marías, um dos autores que salientam a importância desta nota, considera-a justamente o contexto em que Ortega "introduce el término "vivencia» (...) que ha adquirido carta de naturaleza en nuestra lengua”. - MARÍAS, Julián, Ortega. Circunstancia y vocación, op. cit., p. 525 .

101 ORTEGA Y GASSET, José, Sobre el concepto de sensación, op. cit., p. 256 - n. 1.

102 San Martín corrobora esta leitura, reconhecendo na meditação da citada nota um significado genético em relação à filosofia orteguiana posterior: "No creo que se pueda desestimar la importancia que genéticamente pueda tener esa reflexión del Ortega de 1913 para comprender el sentido de la noción de realidad radical así como la frase de Meditaciones del Quijote, recorda[d]a después en el "Prólogo para alemanes": "Tanto la vida social como las demás formas de cultura se nos dan bajo la especie de vida individual". - SAN MARTÍN, Javier, La fenomenologia de Ortega, op. cit., p. 107. 
Com efeito, num contexto de divulgação aos seus compatriotas do método fenomenológico e antes de pôr fim à recensão de Hoffmann, vemos Ortega afastar-se, inequivocamente, do neokantismo e, numa reflexão de cunho próprio, incorporar a fenomenologia como alavanca para a sua filosofia. A dois passos do ano decisivo de 1914, em que irá proferir a conferência Vieja y nueva política e publicar o seu primeiro livro, Meditaciones del Quijote, o pensador espanhol mostra ter discernido cedo, por entre potencialidades do legado husserliano que todo o Século XX viria confirmar, uma trajectória original. No momento que pode considerar-se de recepção da proposta fenomenológica, encontra um poderoso instrumento para filosofar, afinal, para além, tanto da ingenuidade empirista, como do logicismo neokantiano. 
